\title{
Cementing techniques in hip resurfacing
}

\author{
M Chandler ${ }^{1}$, R S Z Kowalski ${ }^{1}$, N D Watkins ${ }^{1 *}$, A Briscoe ${ }^{2}$, and A M R New ${ }^{2}$ \\ ${ }^{1}$ DePuy CMW, Blackpool, UK \\ ${ }^{2}$ Bioengineering Science Research Group, School of Engineering Sciences, University of Southampton, Southampton, UK
}

The manuscript was received on 17 October 2005 and was accepted after revision for publication on 10 November 2005.

DOI: 10.1243/09544119JEIM113

\begin{abstract}
The subject of the cementing technique in hip resurfacing has been poorly studied to date. The hip resurfacing prosthesis is unique in the family of cemented prostheses because the cement mantle is blind (hidden underneath the implant) and is radiographically obscured. This presents an immediate challenge to the surgeon at the time of surgery, but also has a longerterm implication in terms of lack of post-operative clinical observation. This should be compared with total hip replacement or total knee replacement where the cement mantle can at least be partially observed both intra- and post-operatively. With this in mind, the objective of this review is, firstly, to understand the cement mantles typically achieved in current clinical practice and, secondly, to identify those factors affecting the cement mantle and to consolidate them into an improved and reproducible cementing technique. The outcome of this work shows that the low-viscosity technique can commonly lead to excessive cement penetration in the proximal femoral head and an incompletely seated component, whereas a more consistent controlled cement mantle can be achieved with a high-viscosity cementing technique. Consequently, it is recommended that a high-viscosity technique should be used to minimize the build-up of excessive cement, to reduce the temperature created by the exothermic polymerization, and to help to ensure correct seating of the prosthesis. A combination of these factors is potentially critical to the clinical success of some articular surface replacement (ASR) procedures.

It is important to note that we specifically studied the DePuy ASR system; therefore only the general principles (and not the specifics) of the cementing technique may apply to other resurfacing prostheses, because of differences in internal geometry, clearance, and surgical technique.
\end{abstract}

Keywords: bone cement, cementing technique, hip resurfacing

\section{INTRODUCTION}

Acrylic bone cements have been widely used for the fixation of artificial joint replacement implants for many years. The bone cement forms a mantle adjacent to the implant and acts as an elastic zone between the implant and the bone, cushioning the load forces and beneficially affecting bone remodelling whilst sealing the interfaces against ingress of wear particles. Extensive clinical data have confirmed that, when an appropriate cementing technique is applied, acrylic bone cement provides a safe and highly effective fixation method, with results at least as good as cementless procedures.

All acrylic bone cements currently marketed are based on the same chemical substance: methyl

* Corresponding author: DePuy CMW, Cornford Road, Blackpool, Lancashire FY4 4QQ, UK. email: nwatkins@dpygb.jnj.com methacrylate (MMA). Extensive development of MMA and its derivatives began in the 1920s with Otto Rohm, who later founded the Rohm and Haas company. By the 1930s, MMA was used in dentures [1] and the discovery was made that a dough could be produced by mixing poly(methyl methacrylate) (PMMA) with its monomer, MMA, which in turn could be heat cured and hardened in the presence of benzoyl peroxide (BPO) [2]. The heat-cured polymer was used, in a preformed state, to repair cranial defects in humans from the early 1940s [3].

Within a short time, the discovery was made that the polymerization of MMA could be made to occur at room temperature in the presence of a peroxide initiator and an amine activator [4]. This discovery opened the door for 'self-setting' cement in cranial defect repair, in denture repair, and in the development of implant fixation. Kiaer [5] used PMMA as an anchoring material for fixing acrylic caps on 
the femoral head after first removing the cartilage, Haboush [6] used PMMA as a seating compound for a femoral head replacement prosthesis, whilst Sir John Charnley [7] also succeeded in anchoring a femoral head prosthesis in the femur with selfsetting acrylic bone cement.

The adoption of acrylic cement in total hip replacement began in the late 1950s. The first generation cementing technique, generally regarded as having been developed by Charnley, is based on the use of a high-viscosity cement, introduced by hand, digital pressurization, limited bone bed preparation, and open-air cement mixing. A preference to introduce the bone cement with a gun and syringe led to a modified cementing technique, sometimes referred to as second generation. Perhaps owing to the limitations of the early cement guns, a lower-viscosity cement tended to be used. Other refinements were made, including acetabular cement pressurization devices, proximal femoral pressurization devices, and distal cement plugs, these being used to increase cement penetration and to maintain cement pressure above bleeding pressure, preventing blood ingress into the cement. Blood ingress can lead to the creation of blood laminations in cement; a study carried out by Gruen [8] showed that blood laminations can significantly reduce the strength of the acrylic bone cement. Furthermore, it had been recognized, including by Charnley [9], that bone cement functions as a grout and not as a glue. To achieve good fixation to the bone and therefore long-term survival of the implant, the cement must first penetrate the trabecular bone and then harden, forming a physical micro-interlock. As part of the second-generation cementing technique and to increase cement penetration into the bone, improved bone bed preparation was introduced, requiring such factors as irrigation and drying.

As cementing techniques continued to develop, further improvements to bone bed preparation, such as the use of pulsatile lavage, were introduced. Better cement guns were introduced, allowing the use of higher-viscosity cements, and in addition vacuum mixing was used to eliminate cement fumes from the operating theatre and to increase the strength of the cement by porosity removal. It has been acknowledged that the risk of revision for cemented hip replacements is reduced when a modern cementing technique is used compared with early or old techniques [10]. However, it has also been suggested that the risk of revision varies greatly across different orthopaedic clinics even when evaluating optimal techniques $[\mathbf{1 1}, \mathbf{1 2}]$, a finding which suggests that good cementing technique is far from straightforward, and arguably far from understood.

The development of a good cementing technique relies on an understanding of the nature and effect of the handling characteristics of bone cement, these being crucial to achieving good cement penetration and resistance to blood ingress. Bone cement rheology is a complex property, reflecting the viscoelastic behaviour of cements during their curing phase. It can be best thought of as a combination of its stiffness (or elasticity) and its ability to flow. If the bone cement is too stiff and does not flow, then it may not penetrate into the cancellous bone. Conversely, if the cement has high flow without adequate stiffness, then it can be easily displaced by blood unless continuously and meticulously pressurized, and very little cement pressure will be generated during insertion of the prosthesis. Cement viscosity is not constant over time and is affected by environmental factors such as temperature and humidity during storage and use. Furthermore, different commercial brands of cement are available with specific degrees of viscosity and different working and setting times. It is important to understand that all cements eventually reach the same viscosity; however, this will be at different times after mixing. It is therefore critical to appreciate the optimum times for cement introduction, cement pressurization, and implant insertion.

\section{ARTICULAR SURFACE REPLACEMENT CEMENTING}

\subsection{Background}

Resurfacing of the hip is not a new procedure, and the origins of the resurfacing technique predate even total hip replacement (THR). Charnley was one of the pioneers of this technique and had experimented with hip resurfacing designs long before he established the principles of low-friction arthroplasty, which is one of the guiding principles of modern THR.

However, in contrast with the situation for cemented THR, a literature search of cementing technique in hip resurfacing reveals a paucity of data. At the time of writing, prospective clinical data have not been reported in the public domain. Furthermore, findings from cadaveric or animal studies, or even simple bench-top data, are extremely limited. Since knowledge of the cementing technique is most prolific in relation to THR, as a starting point it is necessary to examine whether the same guiding principles can apply to hip resurfacing. 


\subsection{Specific cementing technique for DePuy articular surface replacement}

It is assumed that certain basic principles for hip resurfacing, and in particular for the DePuy articular surface replacement (ASR) system, can be inferred from cemented THR. Firstly, for optimized fixation and load transfer, there must be a complete cement layer covering the entire prepared bone surface. An incomplete cement mantle can lead to mechanical weakness and an opportunity for wear debris ingress, thereby constituting a potential failure site [13]. Secondly, since the central pin of the DePuy ASR femoral prosthesis is designed to be unloaded (a feature which is positively reinforced by the fact that the pin reamer creates a cavity larger than the pin), cement must be prevented from entering the central hole. A cemented pin may result in unloading of the proximal implant, resulting in stress shielding and poor bone remodelling. Thirdly, and arguably most importantly, an excess of cement at the pole must be avoided. Not only do larger cement masses become hotter as the cement cures, but also excess cement at the pole can lead to incomplete seating of the component. This presents a very real danger to the success of the prosthesis and has been positively associated with early failure [14].

An analysis of current hip resurfacing methodologies, of cementing techniques for other joint replacements, and of the types and behaviours of acrylic bone cements leads to the conclusion that cementing techniques used in current hip resurfacing can be categorized into two types.

1. Low-viscosity cementing technique. Cement is poured into the femoral component in as low a viscosity state as possible prior to placement of the prosthesis.

2. High-viscosity cementing technique. Cement is applied to the prepared bone surface in a highviscosity state prior to placement of the prosthesis.

It has been noted previously that the description of the viscosity of bone cements is somewhat arbitrary since variables such as time from mixing and environmental conditions during storage and use will significantly affect the viscosity. All cements can be made to exhibit lower or higher viscosities depending on the interplay of these variables. Nevertheless, it is conventional to classify cements as high or medium viscosity based on how their behaviour compares on a like-for-like basis. Table 1 shows such a classification for several commercial brands of bone cements. It can be inferred that, in
Table 1 Viscosities of commercial bone cements

\begin{tabular}{ll}
\hline High viscosity & Medium viscosity \\
\hline SmartSet GHV (DePuy) & Endurance (DePuy) \\
Palacos R (Schering Plough) & Palamed (Biomet) \\
CMW 1 (DePuy) & Simplex (Stryker Howmedica) \\
\hline
\end{tabular}

general, the high-viscosity cements are more suitable for the resurfacing cementing technique, and the medium-viscosity cements for the low-viscosity technique. However, the differing characteristics of individual cements require that the specific method used in resurfacing must be tailored to an individual cement. It must also be borne in mind that the design of different femoral resurfacing components may significantly affect the result obtained from alternative cements and cementing techniques.

\section{CLINICAL PRACTICE: DESCRIPTION OF THE HIGH-VISCOSITY TECHNIQUE}

What follows is a description of the current clinical practice of Mr Tadgh O'Sullivan (Lourdes Orthopaedic Hospital, Kilkenny, Ireland).

Prior to the application of any cement, a visible mark is made on the bone at the base of the plastic trial piece, using either a pen or a diathermy. This can later be used to verify correct placement of the component, since it is critical to avoid excessive impaction that can lead to microfracture of the bone. (In 25 cases, this marking technique was employed and was found to be accurate on all occasions.)

SmartSet GHV is mixed as per manufacturers instructions and left until 2.0-2.5 min (until not sticky). A pattie is formed of sufficient size to cover the circumference of the femoral head, and approximately $3-4 \mathrm{~mm}$ in thickness. The cement is applied to the head at approximately $4 \mathrm{~min}$ using direct thumb pressure. A neck vacuum vent is placed at the lesser trochanter and a stop is inserted in the guide hole to prevent cement ingress down the guide tunnel. The component is applied at between 4.5 and $6 \mathrm{~min}$, at which point the component can often be seen being sucked down into place to the predetermined length without any further impaction required. It is critical that all the prepared bone is covered by the implant and that all the cement is contained within the component, with no cement left exposed. The high-viscosity cement is easily cleaned away, leaving nothing behind to create debris. The internal taper of the femoral component encourages excess cement to escape, avoiding a large cementophyte at the dome and eliminating the 
initial cement lock as the component is presented to the prepared bone. (Compare this with parallel-sided (cylindrical) components that lock into place as soon as the component touches the bone and have to be forced into place.) To date, this technique has worked successfully with no cases of incomplete seating.

Additionally, the use of high-viscosity cement prevents tissue contamination that can occur with lowviscosity cement, and this type of cement is generally easier to work with, allowing a more controlled procedure. The cement has a longer working time under all temperature conditions, resulting in less time pressure on the operating team to achieve rapid seating of the component, as required with the lowviscosity technique.

Cadaver tests performed by Professor Michael Morlock (Hamburg) demonstrated that under torsional loading there was no failure of the cement interfaces; instead fracture occurred across the femoral neck. It was ascertained that $1-2 \mathrm{~mm}$ of interdigitation and 1-2 mm of cement mantle were optimum for fixation and stability. Minimizing the excess cement in this way also reduces the exothermic cement reaction, thereby helping to mitigate bone avascularity and death.

\section{EXPERIMENTAL STUDIES: CEMENTING TECHNIQUE IN DEPUY ASR}

As has been described, there is little published information concerning the cementing technique for hip resurfacing. To address this, a series of experiments was performed with dual purpose. Firstly, since the cement mantle is 'blind', i.e. restricted from view inside the prosthesis and obstructed radiographically (and therefore arguably unique amongst all cemented prostheses), it was required to observe typical cement mantles achieved using accepted surgical techniques, with emphasis on the depth of cement penetration, the degree of coverage around the bone surface, and the ease of seating of the prosthesis. Secondly, and with these results in mind, it was proposed to define and demonstrate an optimized method to achieve consistent reproducible cement results.

\section{MATERIALS AND METHODS}

\subsection{Experiment 1: influence of cement viscosity (cement type) on interdigitation}

For these studies, the two currently adopted methods of cementing technique were used: (a) low-viscosity cement poured into the prosthesis prior to implantation;

(b) high-viscosity cement applied manually to the bone (finger packed).

SmartSet GHV cement was used for the highviscosity technique and Endurance cement for the low-viscosity technique.

Cadaver studies were performed using four sets of paired femurs (under the guidance of Professor Michael Morlock at the Technical University Hamburg, Germany $[\mathbf{1 5}, \mathbf{1 6}])$. All cements were mixed according to their instructions using the Cemvac vacuum mixing system. Cemvac is a high-vacuum (93 per cent) syringe mixing system designed to eliminate porosity and to provide a fume-free mixing environment. In these experiments it provided reproducible efficient mess-free mixing.

\subsubsection{Low-viscosity technique}

For the low-viscosity technique, Endurance cement was mixed in the Cemvac system using 10-13 strokes of the mixing paddle. This took approximately $30-45 \mathrm{~s}$. (It is important to note that true lowviscosity cements are not commercially common; therefore this technique calls for a medium-viscosity cement that is used very early, whilst still in the wet runny phase.) The cement was immediately extruded (i.e. 45-60 s) from the nozzle into the upturned prosthesis, filling the prosthesis to approximately onequarter of the volume. The prosthesis was swirled to allow cement to flow around the inside of the implant and coat the walls and then quickly implanted on to the prepared bone (at approximately $90 \mathrm{~s})$. It was seated using a standard impactor and the cement was left to harden. The whole process was performed as quickly as possible to ensure that the cement was low viscosity, with all the required hardware and accessories immediately to hand.

Typical timings (low-viscosity technique) are as follows: mix cement, 30-45 s; then immediately extrude cement into prosthesis, 45-60 s; then immediately insert prosthesis, $90 \mathrm{~s}$.

\subsubsection{High-viscosity technique}

For the high-viscosity technique, SmartSet GHV cement was mixed using 10-13 strokes of the mixing paddle and then left until the dough time was reached (i.e. the time at which the cement did not stick to a gloved finger). The dough time of SmartSet GHV was typically $2 \mathrm{~min}$, but this is commonly dependent on storage and theatre temperatures. In our experience, theatre temperatures in different 
hospitals can vary between 18 and $23{ }^{\circ} \mathrm{C}$, and country-to-country variation can result in an even greater range. Cooler temperatures (i.e. towards the lower end of this range) are typically more common, both for the comfort of the theatre staff and also to reduce the spread of infection, but at these temperatures the cement possesses a longer dough time, a longer working time, and a longer setting time. Conversely, warmer temperatures speed up the cement reaction and it is important to know how fast the dough time and setting time can be in the local conditions.

Once the dough time was reached, approximately half of the cement quantity was extruded into the hand, manipulated into a ball, and applied to the bone. The cement was slowly and meticulously finger packed into all areas of the prepared bone surface. Particular care was taken to avoid cement down the central pinhole, since the pin is designed to be unloaded in the DePuy ASR system (to ensure that load transfer occurs directly beneath the bearing surface). Excess cement was removed (with particular attention paid to the proximal-most surface), prior to placement of the prosthesis. Upon seating, a doughy ring of excess cement was collected around the base of the prosthesis; this was removed in good time prior to cement hardening.

Typical timings (high viscosity technique): $\operatorname{mix}$ cement, 45-60 s; extrude cement into hand, 2-3 min; finger-pack cement into bone, 3-4 min; insert prosthesis, 4-5 $\min$.

For each cement type, once the cement had set, the cadaver bones were cross-sectioned using a water-cooled bandsaw, and the sections were analysed for quality and quantity of cement mantle.

\subsection{Experiment 2: effect of cement mantle thickness on exotherm temperature}

The exotherm temperature generated during the cement setting process can be significant; large volumes of cement can commonly achieve up to $90{ }^{\circ} \mathrm{C}$ [17] and can even exceed $100{ }^{\circ} \mathrm{C}$ at their peak temperature. Two methods were developed to evaluate the relevance of the exotherm in a hip resurfacing application.

\subsubsection{Finite element analysis [18]}

A solid model of a femur was generated from computer tomography scans of a cadaveric femur, from a donor of mass $77 \mathrm{~kg}$. For each slice, the outer contour of the femur was defined as a polynomial spline (Mimics, Materialise NV, Leuven). These curves were then lofted together (I-DEAS10 EDS, Texas) to form a geometrical three-dimensional model of the femur. The femur was then virtually implanted with a suitably sized generic design of femoral component (Fig. 1).

Two models were generated in which the prosthesis was considered as having a cemented inner surface, with a thickness of either $1.5 \mathrm{~mm}$ or $3.5 \mathrm{~mm}$. In both cases the metaphasal stem was modelled as debonded and over-reamed over its length. The models were meshed using linear tetrahedral elements. A more refined mesh (1.5-1.6 mm) was used in the head and neck regions, with larger elements (4-6.5 $\mathrm{mm}$ ) being used in the femoral shaft to reduce computational running costs. Material properties were applied to the bone using the freeware program BoneMat [19]. Young's modulus for a bone element was calculated from the average apparent density determined from CT scans and automatically assigned to the finite element (FE) model using Bonemat. The apparent density was related to Young's modulus by

$$
E=7821 \rho^{1.53}
$$

where $E$ is Young's modulus (MPa) and $\rho$ is the apparent density $\left(\mathrm{g} / \mathrm{cm}^{3}\right)$. Poisson's ratio for bone was assumed to be 0.3 . The prosthesis was modelled as having Young's Modulus equal to $200 \mathrm{GPa}$ and Poisson's ratio equal to 0.3 . The PMMA bone cement was modelled as having Young's Modulus equal to $2.8 \mathrm{GPa}$ and Poisson's ratio equal to 0.3.

A thermal analysis was performed to look at the potential impact on thermal necrosis. Polymerization of the bone cement during component fixation generates heat, which causes temperature rises in the cement, prosthesis, and surrounding tissues. Materials properties for the regions of the model corresponding to bone were assigned using data from the literature. The prosthesis was assumed to be manufactured from Co-Cr alloy, and all materials were assumed to be homogeneous and isotropic. Material and other properties required for the specification of the model are shown in Table 2. The temperature of the nodes on the whole of the external surface of the cortical bone was fixed at body temperature $\left[37^{\circ} \mathrm{C}(310 \mathrm{~K})\right]$ throughout the simulation.

Table 2 Material properties ( $T$ is temperature)

\begin{tabular}{llll}
\hline & $\begin{array}{l}\text { Density } \\
\left(\mathrm{kg} / \mathrm{m}^{3}\right)\end{array}$ & $\begin{array}{l}\text { Specific heat } \\
\text { capacity } \\
(\mathrm{J} / \mathrm{kg} \mathrm{K})\end{array}$ & $\begin{array}{l}\text { Thermal } \\
\text { conductivity } \\
\left(\mathrm{W} / \mathrm{m}^{2} \mathrm{~K}\right)\end{array}$ \\
\hline Cortical bone & $2.1 \times 10^{3}$ & $1.26 \times 10^{3}$ & 0.38 \\
Prosthesis & $8.87 \times 10^{3}$ & $0.45 \times 10^{3}$ & 14.6 \\
Bone cement & $1.1 \times 10^{3}$ & $6.5 T+1.25 \times 10^{3}$ & 0.2 \\
\hline
\end{tabular}




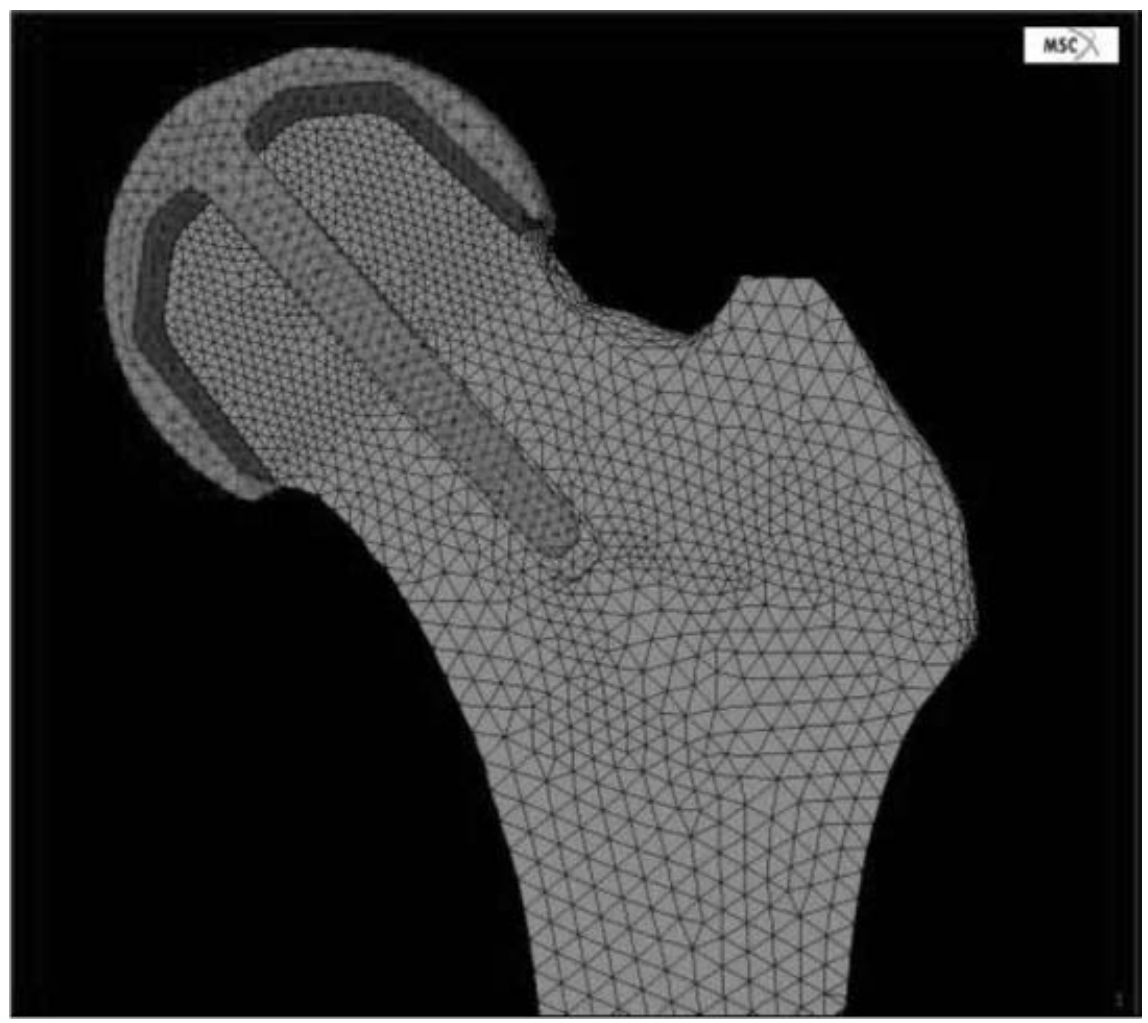

Fig. 1 FE model of a resurfaced femoral head

The initial temperature of the cement and prosthesis was room temperature $\left[23^{\circ} \mathrm{C}(296 \mathrm{~K})\right]$ and the initial temperature of the bone component was body temperature. The cement was given an initial (very small) degree of polymerization $\left(6 \times 10^{-6}\right)$, this being necessary to initiate the polymerization in the numerical model (see below). The cement curing reaction was modelled using the kinetic equation

$$
S=K_{0} \mathrm{e}^{-E_{\mathrm{a}} / R T}\left(\alpha_{\max }-\alpha\right)^{n} \alpha^{m}
$$

relating the instantaneous local volumetric heat generation rate $S$ in the cement, to the local degree $\alpha$ of polymerisation of the cement, and the local temperature $T$ via an exponential function describing the effect of temperature on the reaction rate, where $K_{0}$, $m$, and $n$ are constants, $E_{\mathrm{a}}$ is the activation energy, and $R$ is the universal gas constant. The quantity $\alpha_{\max }$ represents the maximum degree of polymerization, and for the present study was set to unity.

The constant $K_{0}$ and the activation energy $E_{\mathrm{a}}$ used in these equations were determined for CMW $1^{\text {(i) }}$ cement using differential scanning calorimetry. These values and others required for specification of the model are shown in Table 3 . The curing model was incorporated into the FE model using the procedure illustrated in Fig. 2. Each simulation was allowed to run for a total of $2000 \mathrm{~s}$ to ensure complete polymerization throughout the cement mantle and
Table 3 Constants used in heat generation rate calculations

\begin{tabular}{ll}
\hline Equation constant & Value \\
\hline$K_{0}$ & 9484.37 \\
$E_{\mathrm{a}}$ & $31286 \mathrm{~J}$ \\
$R$ & $8.314 \mathrm{~kg} / \mathrm{mol} \mathrm{K}$ \\
$M$ & 0.98 \\
$N$ & 1.064 \\
\hline
\end{tabular}

return of bone temperatures to below the threshold for cell necrosis $\left(44^{\circ} \mathrm{C}\right.$; see below).

Necrosis of the bone is a function of time and temperature. In this study, the necrosis index was calculated at each of three nodes on a line running from the cement-bone interface into the bone, as shown in Fig. 2.

For each node and each time step in the analysis, a necrosis index increment was calculated by dividing the time step size by the time to thermal damage at temperature $T$, where $T$ is the average temperature in the element over the time step. The time to thermal damage at temperature $T$ was calculated using an exponential function fitted to the data of Moritz and Henriques [20]. In order to avoid problems with extrapolating beyond the range of temperatures for which Moritz and Henriques provide data, temperatures above $65{ }^{\circ} \mathrm{C}$ were assumed to cause a necrosis 


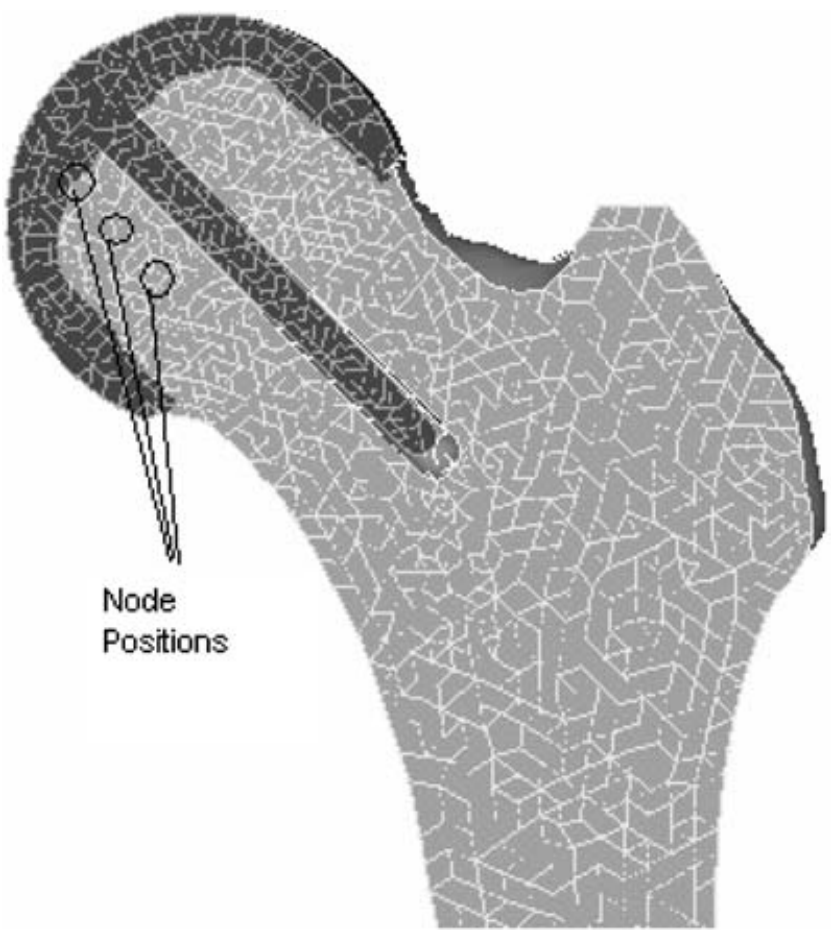

Fig. 2 FE analysis: position of nodes to record temperature

index increment of 1 for the time step, and temperatures below $44{ }^{\circ} \mathrm{C}$ a necrosis index increment of 0 . Finally, the necrosis index increments were summed to calculate the necrosis index, with total values at the end of the analysis greater than 1 indicative of thermal necrosis of the bone (Fig. 3).

\subsubsection{Cement exotherm measurements}

Cement specimen discs (SmartSet GHV) were created in five different thicknesses $(2.5,4,6,9$, and

\begin{tabular}{|c|}
\hline Generate finite element mesh \\
\hline$\downarrow$ \\
\hline Specify materials properties \\
\hline$\downarrow-1+2$ \\
\hline Apply boundary conditions \\
\hline$\downarrow$ \\
\hline $\begin{array}{l}\text { Specify initial conditions (Initial nodal temperatures, initial nodal } \\
\text { degree of polymerisation, initial time step size, } t \text { ) }\end{array}$ \\
\hline \\
\hline Calculate initial nodal heat generation rate \\
\hline$\downarrow$ \\
\hline Solve heat flow equations for nodal temperatures after time step, \\
\hline $\begin{array}{l}\text { Calculate new nodal degree of polymerisation, new nodal heat } \\
\text { generation rate, new time step size (adaptive) }\end{array}$ \\
\hline Polymerisation complete? \\
\hline \\
\hline WYes \\
\hline Stop \\
\hline
\end{tabular}

Fig. 3 Incorporation of the kinetic equation into the FE model
$13 \mathrm{~mm}$ ), and a thermocouple wire was inserted into the exact centre of each cement specimen before the cement was set. This was based on the accepted International standard for acrylic bone cement (ISO 5833:2002 [17]), but with some modifications; a stainless steel plate with a hole of $80 \mathrm{~mm}$ diameter through the middle was used, and placed on to a wooden block to create a solid base. This was intended to mimic crudely a cemented prosthesis, i.e. a thermally conductive metal surface (the prosthesis) against a non-conductive substrate (the bone), in order to model the dissipation of heat away from the cement during the polymerization reaction. The thermocouple wires were attached to a digital reader (Yokogawa 3081 hybrid recorder), and the thermal profile and peak exotherm temperatures were recorded. A graph was plotted of cement thickness versus peak exotherm temperature.

\section{RESULTS}

\subsection{Experiment 1: influence of cement viscosity (cement type) on interdigitation}

\subsubsection{Low-viscosity technique}

There is a significant depth of cement penetration with the low-viscosity technique, typically greater than $10 \mathrm{~mm}$ (Fig. 4). This very large degree of cement penetration is most prominent directly at the pole (or proximal-most part), which is consistent with the pressures exerted in this direction during placement of the prosthesis. Conversely, there is very little, if any, cement penetration around the circumference, consistent with the lack of pressure exerted in this direction during placement of the prosthesis.

Another interesting observation was the incomplete seating of the prosthesis (Fig. 5). This was seen

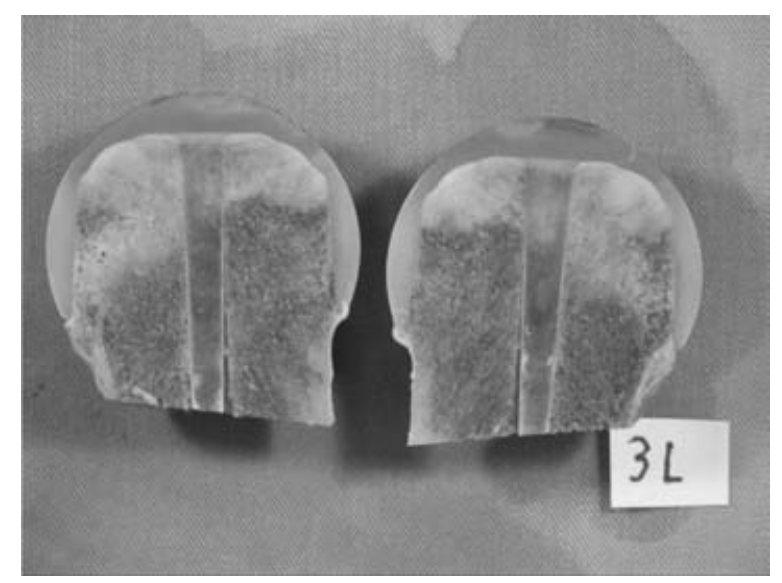

Fig. 4 Low-viscosity cement: excessive penetration 


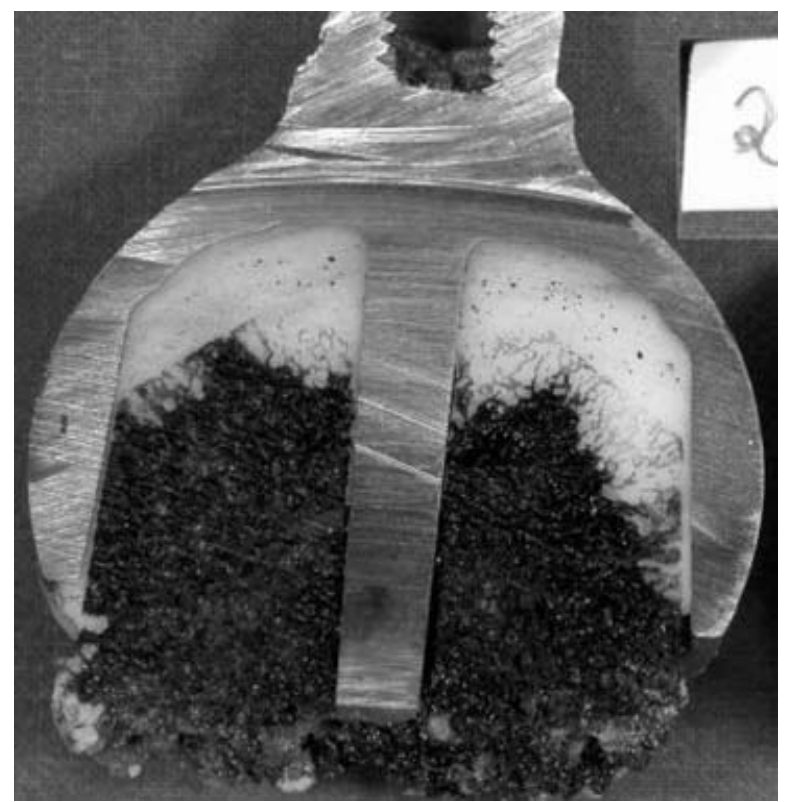

Fig. 5 Low-viscosity cement: incomplete seating

in almost every case and is defined by a clearance of greater than $1 \mathrm{~mm}$ between implant and bone (this is the maximum clearance given by reamers). Specimens were consistently created where the prosthesis had at least $5 \mathrm{~mm}$ of stand-off. In fact, in the very best case the prosthesis was still approximately $2 \mathrm{~mm}$ too high.

\subsubsection{High-viscosity technique}

A much more consistent cement mantle was seen with the high-viscosity technique. The depth of cement penetration was typically $2 \mathrm{~mm}$. A layer of interdigitated cement was present around the entire bone surface (i.e. in all the places it had been applied) (Fig. 6) and, significantly, complete seating of the prostheses was achieved (Fig. 7).

\subsection{Experiment 2: effect of cement mantle thickness on exotherm temperature}

\subsubsection{Finite element analysis}

Increasing the cement thickness increases the extent of the zone of necrosis in the bone surrounding the cement. The thin cement mantle produces a maximum temperature of $47^{\circ} \mathrm{C}$ (Fig. 8); the thick cement mantle produces a maximum temperature of $57{ }^{\circ} \mathrm{C}$ (Fig. 9). This $10^{\circ} \mathrm{C}$ difference in temperature reduces the amount of time that it takes for bone necrosis to take place. It also causes the bone to experience these elevated temperatures for an extended period. These two factors produce a necrosis depth of greater than $2 \mathrm{~mm}$ when a thick cement mantle is used.

\subsubsection{Cement exotherm measurements}

Increasing the cement thickness increases the peak exotherm temperature (Fig. 10). At the maximum thickness $(12.6 \mathrm{~mm})$ the cement achieved a peak curing temperature of $80.8^{\circ} \mathrm{C}$. At the minimum thickness $(2.5 \mathrm{~mm})$ the cement achieved a peak curing temperature of $37.4^{\circ} \mathrm{C}$.

\section{DISCUSSION}

During the course of these experiments a number of factors were evaluated that may be important to the

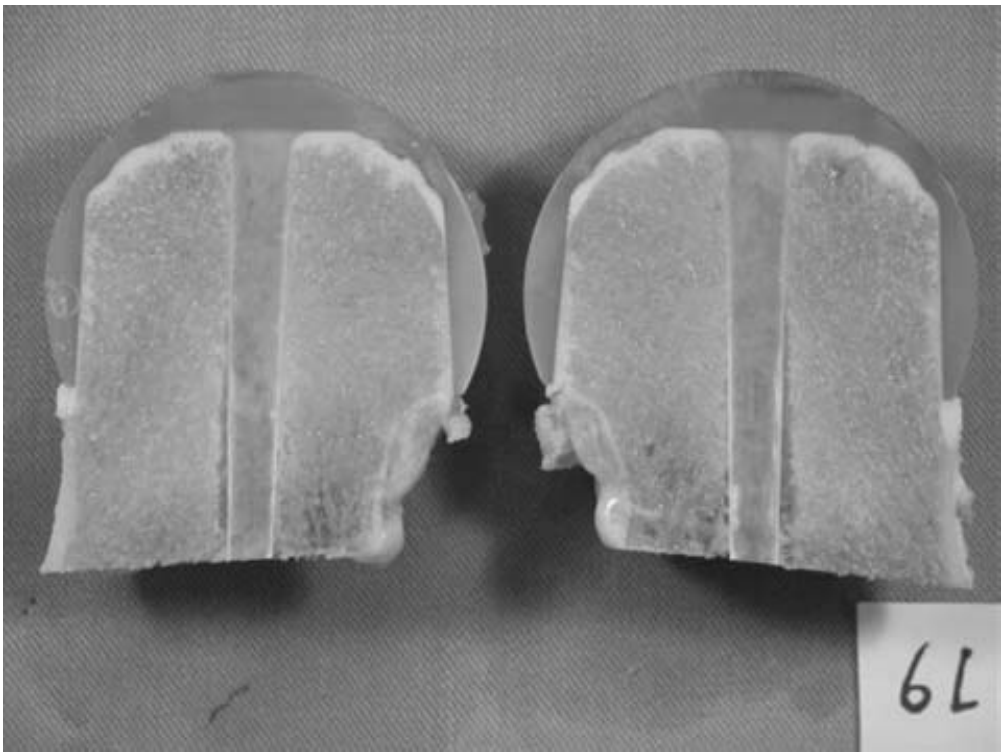

Fig. 6 High-viscosity cement: controlled even interdigitation 


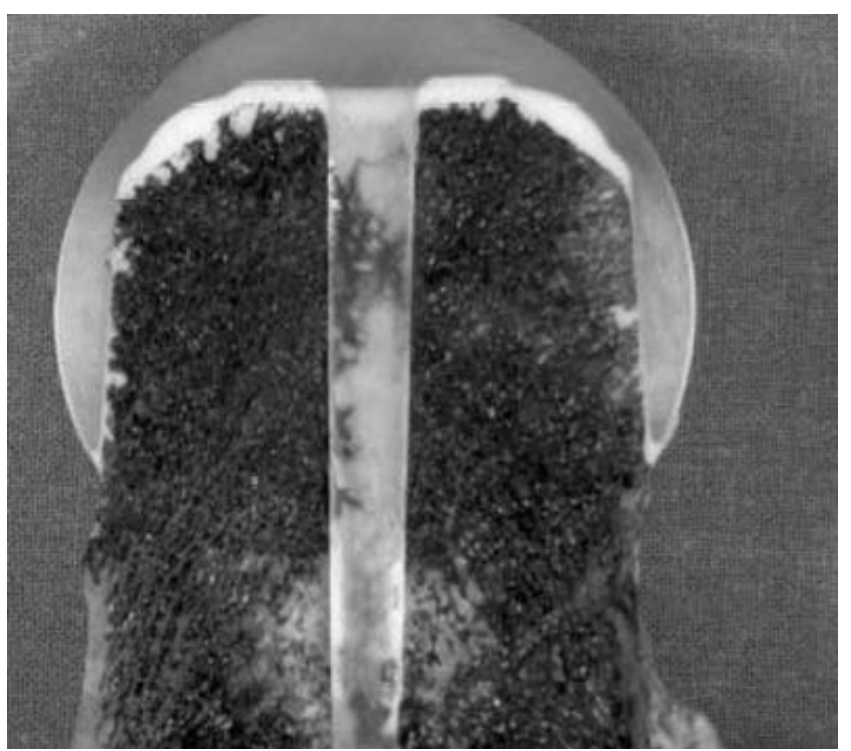

Fig. 7 High-viscosity cement: complete seating

correct implantation and subsequent clinical success of the ASR resurfacing prosthesis. These factors can be combined to create a set of guidelines for optimized clinical implantation with respect to cementing technique.
The outcome of this work shows that the lowviscosity technique can commonly lead to excessive cement penetration in the proximal femoral head, and that a more consistent controlled cement mantle can be achieved with the high-viscosity technique. Consequently an appropriate technique should be used to minimize the build-up of excessive cement, which in turn helps to reduce the exothermic cement temperature and also helps to ensure correct seating of the prosthesis.

The cement polymerization reaction involves the conversion of liquid momomer (MMA) to solid polymer (PMMA). This is a free-radical polymerization, induced and controlled by the availability of a peroxide initiator (BPO) in the powder and an amine activator (dimethyl $p$-toluidine) in the liquid. The conversion of monomer to polymer results in the creation of energy, and this energy is released as heat. Since the quantity of energy is directly related to the quantity of cement, larger masses became hotter than smaller masses.

At first, this would appear a significant issue, considering that protein denaturation occurs at $44^{\circ} \mathrm{C}$, with the associated risk of thermal necrosis to bone and soft tissue. However, in the case of a

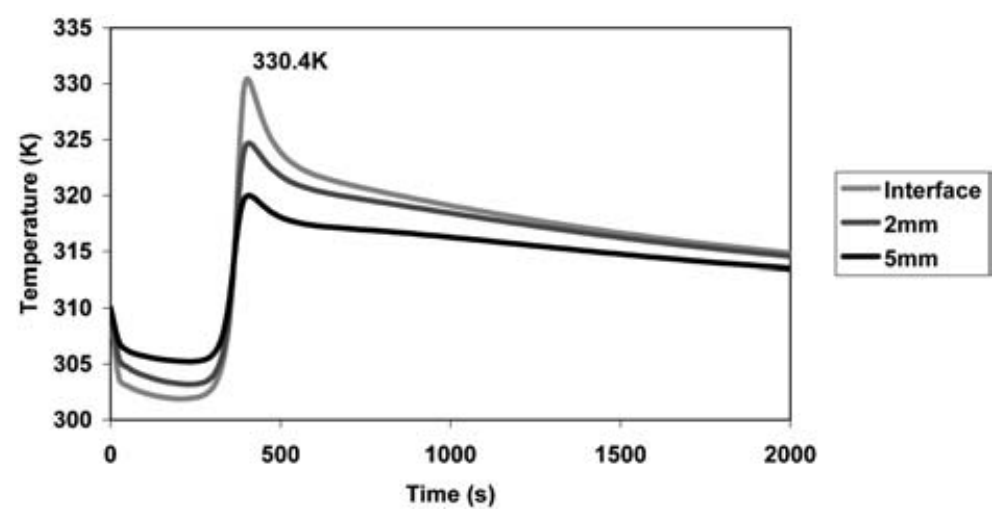

Fig. 8 FE exotherm temperature for a thin cement mantle

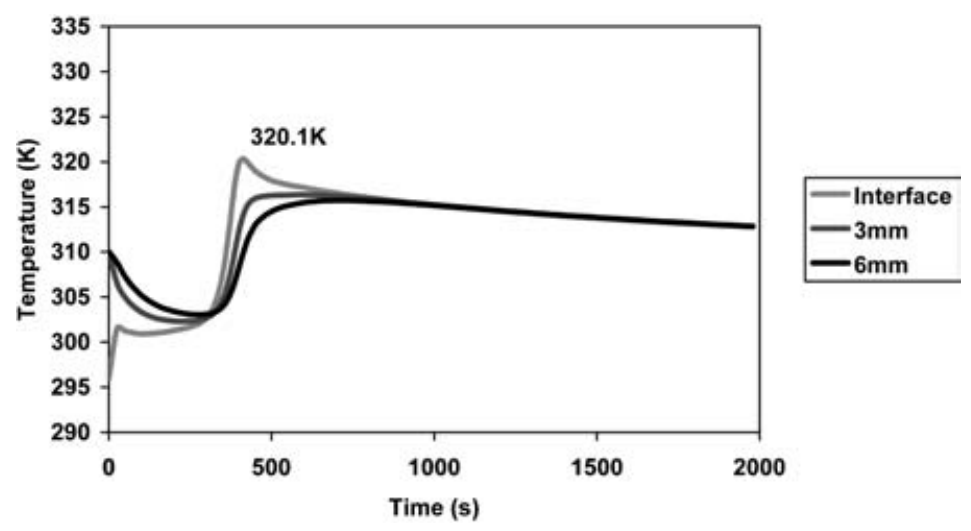

Fig. 9 FE exotherm temperature for a thick cement mantle 


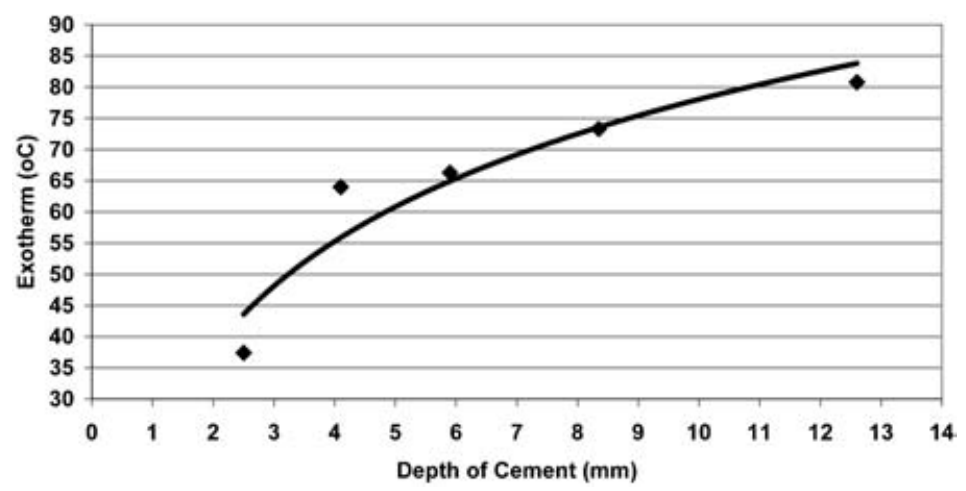

Fig. 10 Cement thickness versus peak exotherm temperature

conventional cemented femoral component (in THR), a number of factors may potentially combine to mitigate the thermal risk: the relatively large bulk of the metal hip prosthesis, the large surface area of the cement mantle, and the fluid flow around the femur, all acting as heat sinks, dissipating heat away from the cement. Kuhn [21] discussed the fact that, whilst the cement exotherm can achieve above $80{ }^{\circ} \mathrm{C}$ in the laboratory (using the procedure in ISO 5833:2002 [17], for example), this only translates to a maximum of $40-50{ }^{\circ} \mathrm{C}$ in the clinical setting (in a conventional cemented femoral stem, for example). However, there are differences between a cemented femoral stem and a hip resurfacing construct; the large implant, surface area, and fluid flow are not as significant in resurfacing; so a controlled technique is required and the creation of an optimum cement mantle is vital.

\section{CONCLUSION}

The outcome of this work shows that the lowviscosity technique can commonly lead to excessive cement penetration in the proximal femoral head, and that a more consistent controlled cement mantle can be achieved with the high-viscosity technique. Consequently, it is prudent to recommend that an appropriate technique should be used to minimize the build-up of excessive cement, which in turn helps to reduce the exothermic cement temperature and also helps to ensure correct seating of the prosthesis. A combination of these factors is potentially important to the clinical success of the ASR resurfacing procedure.

\section{ACKNOWLEDGEMENTS}

The present authors acknowledge Mr Tadgh O'Sullivan for his input regarding cementing technique in clinical practice. They acknowledge Professor Michael Morlock and Dr Nick Bishop (Technical University Hamburg, Germany) for their guidance and expertise in the cadaver studies and mechanical testing, and also Dr Mark Taylor, Dr Andrew New, and Adam Briscoe (all University of Southampton, UK) for their guidance and expertise in the FE Analyses.

\section{REFERENCES}

1 Bauer, W. Rohm \& Haas, DRP Patent 652821, Verfahren zür Herstellung Prothesen für zarnarztliche 2 weche, 1935.

2 Kulzer \& Co., GmbH, DRP Patent 737058, Verfahren zür Herstellung von Prothesen für zarnarztliche order andere zweck aus polymerisierten organischen Verbindungen, 1936.

3 Kleinschmitt, o. Plexiglas zur Deckund von Schadellucken. Chirurg, 1941, 13, 273.

4 Kulzer \& Co., GmbH, DRP Patent 973590, Verfahren zür Herstellung von Prothesen für zahnarztliche order andere zweck aus polymerisierten organischen Verbindungen, 1943.

5 Kiaer, S. Preliminary report on arthroplasty by the use of acrylic head. Cliniquiem Congress International de Chirurgie Orthopedique, Stockholm, 1951.

6 Haboush, E. J. A new operation for arthroplasty of the hip based on biomechanics, photoelasticity, fast setting dental acrylic and other considerations. Bull. Hosp. Jt Dis. N.Y., 1953, 14, 242-277.

7 Charnley, J. Anchorage of the femoral head prosthesis of the shaft of the femur. J. Bone Jt Surg., 1960, 42B, 28-30.

8 Gruen, T. A., Markoff, K. L., and Amstutz, H. C. Effects of laminations and blood entrapment on the strength of acrylic bone cement. Clin. Orthop. Rel. Res., 1976, 119, 250-255.

9 Charnley, J. Acrylic Cement in Orthopaedic Surgery, 1972, p. 19 (Churchill Livingstone, Edinburgh).

10 Malchau, H. and Herberts, P. Prognosis of total hip replacement, surgical and cementing technique in THR: a revision-risk study of 134,056 primary operations. Scientific Exhibition Presented at the 
62nd Annual Meeting of the American Academy of Orthopaedic Surgeons, Atlanta, Georgia, USA, 22-26 February, pp. 1-12.

11 Havelin, L., et al. Prospective Studies of Hip Prosthesis and Cements: A Presentation of the Norwegian Arthroplasty Register 1987-1999, p. 7.

12 Malchau, H. and Herberts, P. How outcome studies have changed total hip arthroplasty practices in Sweden. Clin. Orthop., 1997, 344, 44-60.

13 Amstutz, H. C. History of hip resurfacing, University of California, Los Angeles, Medical Center, http: //www.jri-oh.com/hipsurgery/Surface.asp.

14 Amstutz, H. C. Fracture of the neck of femur after surface arthroplasty of the hip. J. Bone Jt Surg., 2004, 86A(9), 1874-1877.

15 Bishop, N. and Morlock, M. Effect of high and low viscosity cementing technique on cement penetration and torsional stability. Unpublished data, November 2003.

16 Bishop, N. ASR hip resurfacing femoral component: influence of cementing technique on cement pene- tration and distribution - a study with cadaveric femoral heads. Unpublished data, June 2004.

17 ISO 5833:2002, Implants for surgery - acrylic resin cements, 2002 (International Standardization Organization, Geneva).

18 Briscoe, A., Taylor, M., and New, A. The potential for bone thermal necrosis during cementation of the femoral head resurfacing component. Unpublished data, School of Engineering Sciences, University of Southampton, April 2004.

19 Zannoni, C., Mantovani, R., and Viceconti, M. Material properties assignment to finite element models of bone structures: a new method. Med. Engng Physics, 1998, 20(10), 735-740.

20 Moritz, A. R. and Henriques, F. C. The relative importance of time and surface temperature in the causation of cutaneous burns. Am. J. Pathol., 1947, 23, 695-720.

21 Kuhn, K. D. Bone Cements: Up-to-Date Comparison of Physical and Chemical Properties of Commercial Materials, 2000, p. 27 (Springer-Verlag, New York). 